\title{
The use of zeolites for biogas purification in agricultural production
}

\author{
Varvara Druzyanova ${ }^{1,2, *}$, Sofya Petrova $^{1,2}$, Nadezhda Khiterkheeva $^{1,3}$, Irina Bardamova ${ }^{4}$, \\ and Tatyana Gergenova ${ }^{3}$ \\ ${ }^{1}$ North-Eastern Federal University in Yakutsk (NEFU), 58, Belinsky str., 677027, Yakutsk, Russia \\ ${ }^{2}$ Yakut State Agricultural Academy (Branch an Oktemtsy), 16, Moiseev Lane, 678011, Oktemtsy, \\ Russia \\ ${ }^{3}$ Banzarov Buryat State University, 24a, Smolina str., 670000, Ulan Ude, Russia \\ ${ }^{4}$ Russian Academy of Sciences Geological Institute of SB RAS, 6a, Sakhyanov, 670047, Ulan-Ude, \\ Russia
}

\begin{abstract}
The article refers to studies related to the purification of biogas. Biogas is obtained by fermenting of native manure. Biogas is obtained as a result of fermentation of native manure with subsequent purification from unwanted impurities. After purification, the content of methane in biofuel rises, therefore the quality of alternative fuel improves. The results of studies on the use of natural zeolites of the Khonguruu deposit in the Suntarskyulus of the Republic of Sakha (Yakutia) as a filter material are presented. The device of the filter for biogas is described.The materials for planning a multifactorial experiment are briefly presented. The most significant factors of the biogas purification process have been specified: size of fractions, zeolite mass, ratio of the height of bulk material to the diameter of the filter. It is shown that the maximum efficiency of biogas purification was obtained with the ratio of the height and diameter of the filter $\mathrm{H} / \mathrm{d}=3.0: 4.2$. The optimal average weighted diameter of the granules of the bulk filter material (zeolite) is $0.004 \mathrm{~m}$. The optimum mass of the filter material is $0.75-0.8 \mathrm{~kg}$. At the filter outlet, biogas with 93.3\%of methane content was obtained.
\end{abstract}

\section{Introduction}

The uncontrolled use of agricultural waste is rather dangerous for the environment and human health. In this regard, the problem of cultivation and production of environmentally friendly crop and livestock products is greatly aggravated. Provision of environmental safety in agricultural production mostly depends on the introduction of new innovative technologies, which also include low level waste and resources saving technological processes.

Population growth and intensification of agriculture have led to an increase in environmental pollution by harmful substances. A large number of them enter the atmosphere, soil, water sources accompanied by contamination of livestock feed, food and result in global environmental problems.

*Corresponding author: druzvar@mai.ru 
One of the ways to solve environmental and energy problems is the agricultural waste recycling, with the production of organic fertilizers and motor biogas. Besides, while waste recycling, at the same time not only the sanitary condition of the round the farm territories improves but the pathogens of infectious diseases are destroyed, unpleasant odors disappear, and weed seeds die. The constant increase of oil fuel prices, as well as the difficulty of its delivering to remote rural areas promote the development of the biogas industry. For the agro-industrial complex, the situation arises when the use of modern biogas technologies is not only profitable, but it is also the only possible way to meet one's energy needs, especially for remote regions of Russia.

One of the ways to provide environmental safety in agricultural production is to use alternative fuels, including biogas obtained directly at the site of peasant farms with their life activities' waste generation while growing cattle, poultry and other farm animals.

Many factors influence on the composition of the produced biogas: location of the livestock complex, type of feed, environmental conditions, holding period of fermented manure, temperature of the process (mesophilic, thermophilic, psychrophilic), moisture of manure, frequency of mixing of the substrate in the digester. The resulting biogas contains $60-70 \%$ of methane and other gases. Impurities (hydrogen sulfide, nitrogen and carbon oxides) adversely affect the operation of the fuel system of agricultural machines. Burning and interacting with water vapor, the impurities form acid residues, which result in increased before time wear and tear of mechanisms. So the need to clean up biogas arises.

The use of filters for biogas purification improves fuel quality, reduces harmful effect of emissions into the environment, increases durability and performance of agricultural machinery under the conditions of remote areas of the Republic of Sakha (Yakutia) (RSYa for short).

\section{Materials and Methods}

Biogas can be cleaned up in many ways. Recently, natural and artificial zeolites have become widespread in the world as a filter material. RSYa is rich in this material. There are explored deposits in it. There are large reserves of zeolites in the Suntar district of RSYa. The deposit is called Khongurinsky. The exploration work completed. The amount of the "Khonguruu" zeolite reserves is 11462 thousand tons.

Table 1 shows the chemical composition of the zeolite feedstock in the Khonguruu deposit; physicochemical properties of natural zeolites $[1,2]$.

Table 1. The chemical composition of the zeolite feedstock of the Khonguruu deposit, \%.

\begin{tabular}{|c|c|c|c|c|c|c|c|c|}
\hline SiO2 & Al2O3 & Fe2O3 & CaO & MgO & $\begin{array}{c}\text { K2O+ } \\
\text { Na2O }\end{array}$ & TiO2 & H2O & admixture \\
\hline 64.11 & 12.16 & 1.08 & 2.62 & 1.88 & 3.30 & 0.13 & 8.89 & 4.26 \\
\hline
\end{tabular}

The zeolite feedstock of the Khonguruu deposit unlike the feedstock of other similar deposits in the CIS and Russia is characterized by an exceptionally high content of clinoptilolite-heulandite minerals (the zeolite content in the rock is $70-98 \%$ ). After removing water during the drying process, the zeolite is a microporous crystalline "sponge" with a pore content of up to $50 \%$ of the volume of the frame. It is this characteristic that determines the relevance and necessity of using the zeolite products for cleaning in various branches of industry $[3,4]$. It is the zeolites of the Khonguruu deposit that are used as the test material in filters for biogas purification.

In its chemical composition, biogas resembles natural gas and can be used in automotive internal combustion engines. According to the data of Swedish and Swiss scientists, biogas can be used in internal combustion engines, because biogas is $75 \%$ cleaner than diesel fuel and $50 \%$ cleaner than gasoline by environmental characteristics. 
The toxicity of biogas for humans is $60 \%$ lower than of traditional fuels [5-7]. In biogas, the ratio between methane $(\mathrm{CH} 4)$ and carbon dioxide $(\mathrm{CO} 2)$ depends on the initial substrate and characteristic of the fermentation process in the digester. The diagram (Fig. 1) shows the chemical composition of biogas.

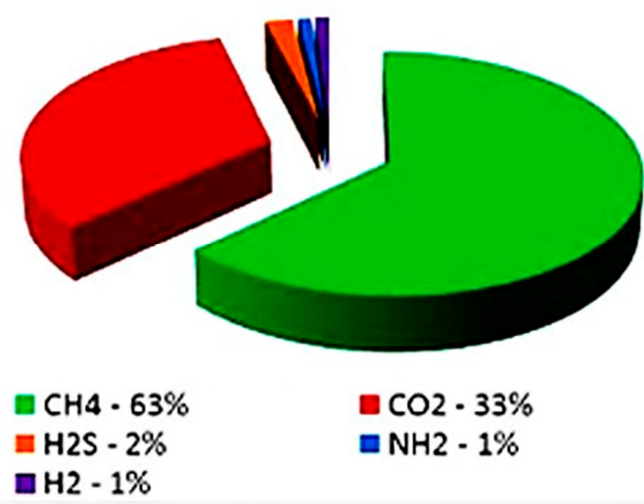

Fig. 1. Impurity content in biogas.

The zeolite filter retains $\mathrm{CO} 2$ molecules having size comparable to the size of zeolite micropores, for example, micropores in the Khongurin zeolite have a size of $0.4 \mathrm{~nm}$ and a $\mathrm{CO} 2$ molecule of $0.31 \mathrm{~nm}$ (see Table 2). The size of the CH4 molecule is less than $0.2 \mathrm{~nm}$, so they will pass freely through the zeolite filter, as it is required. That is, at the outlet of the filter there will be purified methane $[8,9]$.

Table 2. The comparison of the sizes of gas molecules and zeolite pores.

\begin{tabular}{|c|c|c|c|c|c|c|}
\hline \multirow{2}{*}{ Sizes } & \multirow{2}{*}{$\begin{array}{c}\text { Zeolite pore } \\
\text { sizes }\end{array}$} & \multicolumn{6}{|c|}{ Molecule sizes, $\mathbf{n m}$} \\
\cline { 3 - 7 } & $\mathbf{H}_{\mathbf{2}} \mathbf{S}$ & $\mathbf{C O}_{\mathbf{2}}$ & $\mathbf{H}_{\mathbf{2}} \mathbf{O}$ & $\mathbf{C O}$ & $\mathbf{N H}_{\mathbf{3}}$ \\
\hline $\begin{array}{c}\text { Unit of concentration in } \\
\text { parts per million (ppM) }\end{array}$ & $300-500$ & 7.2 & 0.31 & 29 & 17.5 & 28.2 \\
\hline $\begin{array}{c}\text { Molecule sizes/ pore } \\
\text { sizes }\end{array}$ & $0.3-0.5$ & 10.2 & 0.57 & 0.276 & 20.38 & 19.96 \\
\hline
\end{tabular}

Thus, the possibility of using the natural zeolite of the Khongurinsky deposit as a filtering element for biogas purification is confirmed.

Biogas was obtained in a laboratory installation according to the technological scheme shown in Figure 2. 


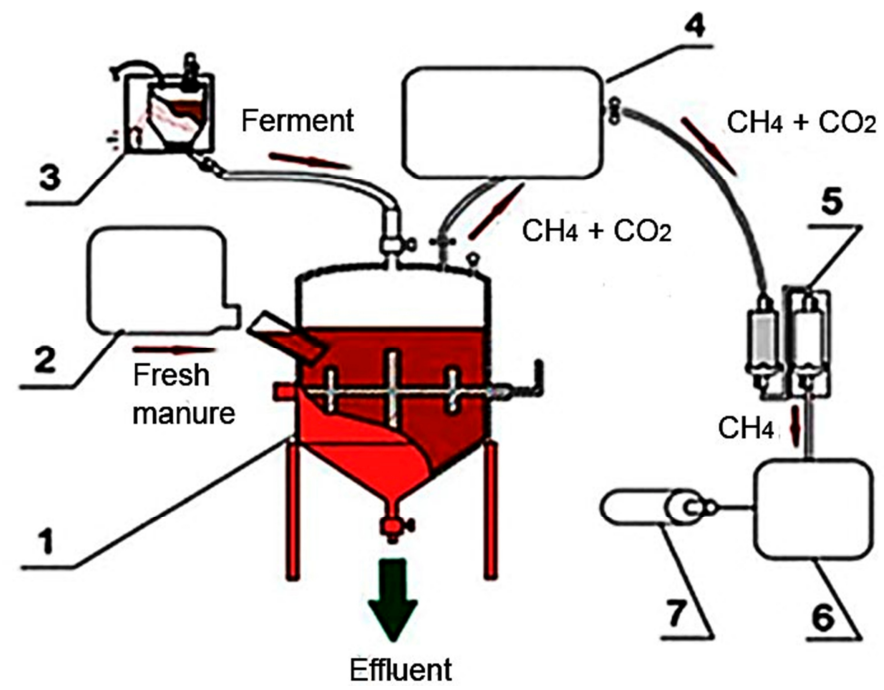

Fig. 2. The principal schematic diagram of the laboratory installation of anaerobic processing of cattle manure with unprotected bedding: 1-digester; 2-capacity for the homogenization of native manure with water; 3-adaptation installation; 4-dry gas holder; 5 - filter for biogas purification; 6 - high pressure compressor; 7 - gas cylinder.

At the beginning of the process, mesophilic methanogens were adapted to psychrophilic conditions in the installation 3. The ferment was used that accelerated the process of anaerobic decomposition of fresh cattle manure. In tank 2, the initial components of manure and water were homogenized. The ferment was supplied from installation 3 to digester 1 , and prepared fresh manure was loaded from fermentation tank 2 to fermentation. The substrate (effluent) obtained as a result of fermentation in a digester is a high-quality organic fertilizer. The biogas obtained in the digester is an accompanying product of anaerobic fermentation. It was collected in a dry gas holder 4. From there it was sucked in by a high-pressure compressor 6 . At the same time, the biogas passed through a filter with zeolite filler 5. Compressor 6 loaded the purified biogas into gas cylinders 7. Mixing was carried out with a hand mixer daily at the same time. The main purpose of mixing is the release of the formed biogas.

The mixing of substrate inside the digester provides an even distribution of bacterial populations and prevents the formation of voids and clusters that reduce the effective area of the digester [10]. The average productivity of this technology was $0.3 \mathrm{~m}^{3}$ of biogas per day [11]. filter.

The biogas passed through an AMT-03 gas analyzer before and after purification in the

A review and analysis of the filters used in the power supply system of a car with gas equipment is carried out. It was revealed that the filters in the fuel system should be compact and have a collapsible design to replace the filter element. In our case, a housing was used from the fuel pre-filter for the KamAZ-740 automobile. The following changes were made to its design (Figure 3): input and output fittings were installed; an adapter was made for attaching the housing cover and gas pipeline; a baffle to the gas pipeline was installed.

This filter works as follows. The biogas enters the filter housing 2 through the gas supply fitting 10, passing through the central channel 9 and passing upward (methane is lighter than air) through the lower partition 1 of the filter element, then it enters the layer of zeolite granules. Here, the biogas is removed from harmful impurities: hydrogen sulfide, carbon dioxide, which settle in the zeolite pores. The purified biomethane has passed 
through the upper baffle and exited through the outlet 7 . The filtering material (zeolite) as it becomes dirty can be regenerated by heating to $200^{\circ} \mathrm{C}$.

The next step was to determine the design parameters of the filters for experimental research. For this procedure, the filters of various sizes were used: height $-0.5 ; 0.4 ; 0.3$; $0.2 ; 0.15 \mathrm{~m}$ its diameter was $0.06 ; 0.08 ; 0.10 ; 0.12 ; 0.14 \mathrm{~m}$; according to the number in the conducted experiment. All filters were filled with a zeolite fraction of $0.004 \mathrm{~m}$ and the biogas with different methane content passed through them, then the degree of purification was determined. In each experiment before and after filter cleaning, the biogas composition was measured for determining the content of $\mathrm{CH} 4$ by the AMT-3 gas analyzer. At the end of each experiment adsorbents were measured by weighing on a laboratory balance model ACOMJW-1.

After developing the filter design, the dependences of the adsorption properties of the zeolite on the size of the fractions were determined. To do this, the zeolite was poured into the designed filter, and its bulk volume was measured.

Using the technique of multifactorial experiment, a research plan has been developed [12]. Figure 4 shows a priori ranking diagram while studying the filtering process. According to the results of a priori ranking, the most influential factors were determined: the size of the zeolite granules; the zeolite mass in the filter; the ratio of height to filter diameter.

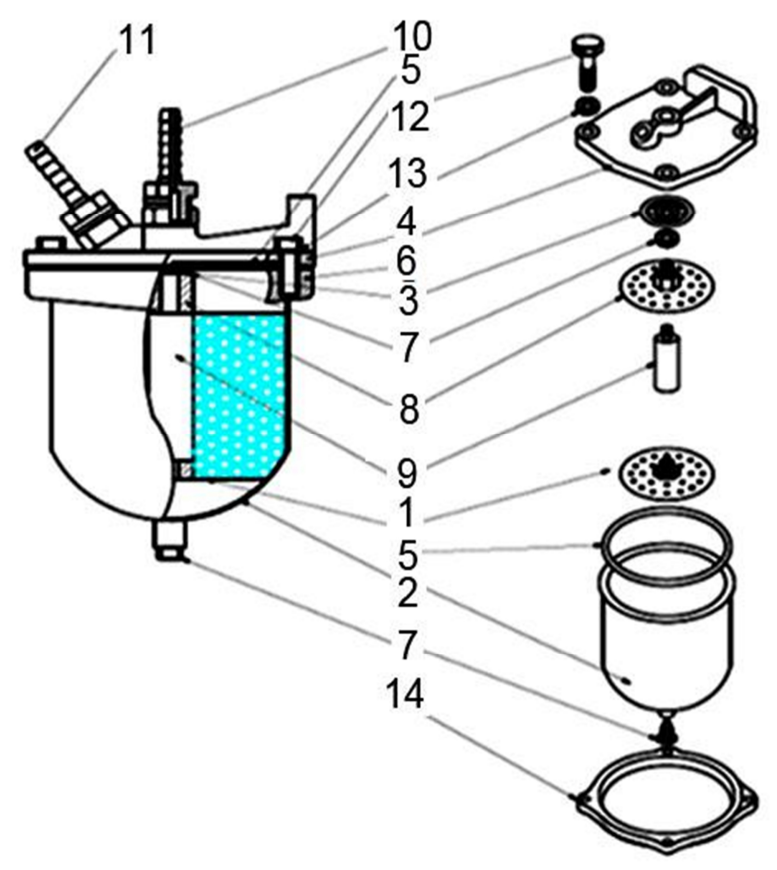

Fig. 3. The biogas purification filter: 1 - lower baffle of the filter element; 2 - filter housing; 3 distributor; 4 - filter cover; 5 - sealing ring; 6 - flange of glass; 7 - spring washer 14; 8 - upper baffle of the filter element with adapter; 9 - the central channel; 10 - fitting for supplying biogas; 11 - fitting for biogas outlet; 12 - bolt; 13 - spring washer; 14 - flange of glass. 


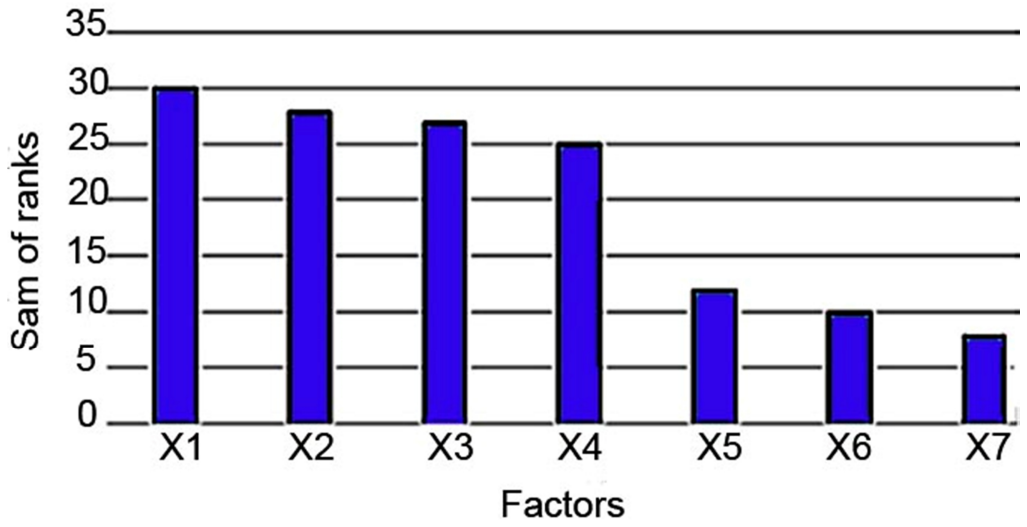

Fig. 4 The average a priori ranking diagram when studying the filtration process: $x 1$ - weighted average sizes of zeolite granules, $\mathrm{mm} ; x 2$ - zeolite mass in the filter, g; $x 3$ - ratio of filter height to its diameter; $x 4$ - methane concentration in biogas, $\% ; x 5$ - biogas humidity, $\% ; x 6$ - biogas supply pressure, $\mathrm{MPa} ; x 7$ - biogas temperature, $\mathrm{K}$.

Table 3 summarizes the factors and the scope of their research, and Table 4 shows the plan matrix and the levels of their variation.

Table 3. The factors and the scope of their research.

\begin{tabular}{|c|c|c|c|c|c|c|c|c|}
\hline \multirow[b]{2}{*}{ Factor } & \multirow[b]{2}{*}{$\stackrel{\mathscr{B}}{\Xi}$} & \multicolumn{3}{|c|}{ Level of real value } & \multirow[b]{2}{*}{ Code } & \multicolumn{3}{|c|}{ Coded value level } \\
\hline & & בְ & $\stackrel{\Xi}{\tilde{E}}$ & $\stackrel{50}{0.00}$ & & בְ & $\sum^{\Xi}$ & $\stackrel{50}{0.00}$ \\
\hline $\begin{array}{l}\text { The weighted average sizes of } \\
\text { granules, } \mathrm{mm}\end{array}$ & $\mathrm{d}$ & 2 & 4 & 6 & $\mathrm{x}_{1}$ & -1 & 0 & +1 \\
\hline The zeolite mass in the filter, $g$ & $\mathrm{~m}$ & 500 & 750 & 1000 & $\mathrm{x}_{2}$ & -1 & 0 & +1 \\
\hline $\begin{array}{l}\text { Ratio of filter height to } \\
\text { diameter }\end{array}$ & $\mathrm{H} / \mathrm{d}$ & 2.5 & 3.25 & 4 & $\mathrm{x}_{3}$ & -1 & 0 & +1 \\
\hline
\end{tabular}

Table 4. The matrix of the plan and the level of factors variation.

\begin{tabular}{|c|c|c|c|c|}
\hline \multirow{2}{*}{\begin{tabular}{c}
$\qquad$ \\
\cline { 2 - 4 }
\end{tabular}} & $\begin{array}{c}\text { The weighted average sizes of } \\
\text { granules, mm }\end{array}$ & $\begin{array}{c}\text { The zeolite mass } \\
\text { in the filter, } \mathbf{g}\end{array}$ & $\begin{array}{c}\text { Ratio of filter height } \\
\text { to diameter }\end{array}$ & $\begin{array}{c}\text { Y \% of } \\
\text { methane } \\
\text { from biogas }\end{array}$ \\
\hline 1 & 1 & 1 & 0 & 70 \\
\hline 2 & -1 & -1 & 0 & 80 \\
\hline 3 & 1 & -1 & 0 & 75 \\
\hline 4 & -1 & 1 & 0 & 82 \\
\hline 5 & 1 & 0 & 1 & 76 \\
\hline 6 & -1 & 0 & -1 & 85 \\
\hline 7 & 1 & 0 & -1 & 72 \\
\hline 8 & -1 & 0 & 1 & 87 \\
\hline 9 & 0 & 1 & 1 & 92 \\
\hline 10 & 0 & -1 & -1 & 78 \\
\hline 11 & 0 & 1 & -1 & 90 \\
\hline 12 & 0 & -1 & 1 & 84 \\
\hline 13 & 0 & 0 & 0 & 95 \\
\hline 14 & 0 & 0 & -1 & 90 \\
\hline 15 & 0 & 0 & 1 & 84 \\
\hline
\end{tabular}


The degree of gas purification efficiency was determined by the formula (1) [13]:

$$
\mathrm{E}=\frac{\mathrm{C}_{\mathrm{P}}-\mathrm{C}_{\mathrm{D}}}{\mathrm{C}_{\mathrm{P}}} * 100 \%
$$

where - E degree of gas purification, \%; $C_{D}$ - methane content in biogas before purification; $\mathrm{C}_{\mathrm{P}}$ - methane content in biogas after purification.

\section{Results}

The comparative tests under identical conditions for the efficiency of biogas purification are summarized in Table 5. The results have showed that a filter with weighted average granule diameters of zeolite particles of $0.004 \mathrm{~m}$ has a maximum percentage of purification $[14,15]$. Figure 5 shows the experimental data and the theoretical curve obtained by approximation by a polynomial.

Table 5. The efficiency of biogas purification depending on the size of zeolite fractions.

\begin{tabular}{|c|c|c|c|c|}
\hline \multirow{2}{*}{ № of experiment } & \multicolumn{5}{|c|}{ Diameter of particles $\boldsymbol{d}, \mathbf{m}$} \\
\cline { 2 - 5 } & $\mathbf{0 . 0 0 2}$ & $\mathbf{0 . 0 0 3}$ & $\mathbf{0 . 0 0 4}$ & $\mathbf{0 . 0 0 5}$ \\
\cline { 2 - 5 } & \multicolumn{4}{|c|}{ Efficiency of purification, $\boldsymbol{E} \%$} \\
\hline 1 & 56 & 73 & 92 & 80 \\
\hline 2 & 62 & 75 & 95 & 76 \\
\hline 3 & 66 & 83 & 92 & 75 \\
\hline 4 & 63 & 88 & 90 & 81 \\
\hline 5 & 62 & 83 & 86 & 78 \\
\hline Average value of experiments & 62 & 80 & 91 & 78 \\
\hline
\end{tabular}

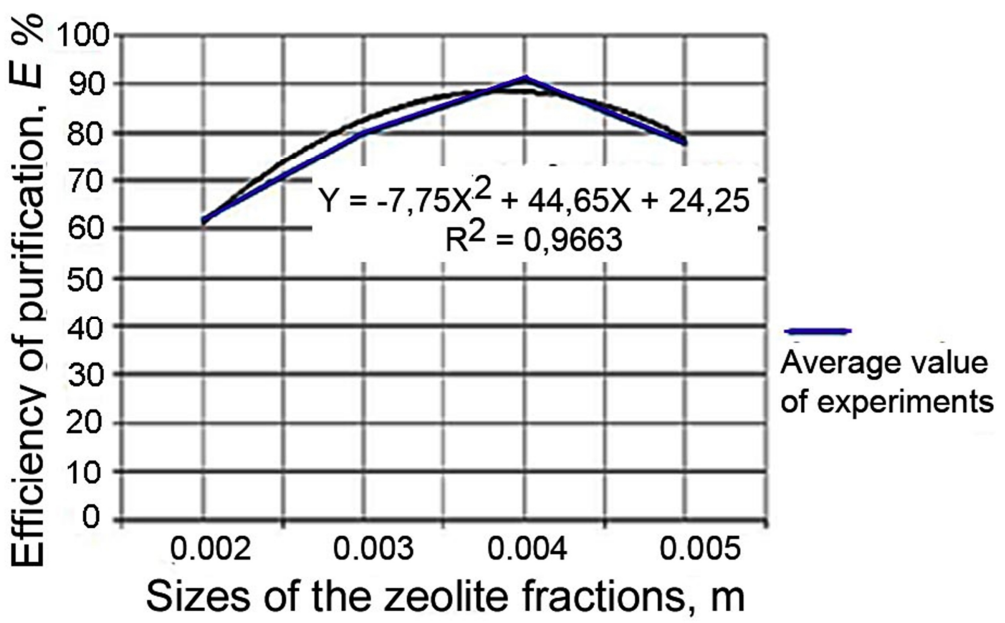

Fig. 5. The dependence of the biogas purification efficiency on the size of zeolite fractions.

The dependence of the biogas purification efficiency on the ratio of the geometric dimensions of the filter $(\mathrm{H}$ - height $)$ and $(\mathrm{d}$ - diameter) are shown in the Table 6. Figure 6 presents a graphical interpretation. 
Table 6. The results of the efficiency of the biogas purification depending on the filter design parameters.

\begin{tabular}{|c|c|c|c|c|c|}
\hline \multirow{2}{*}{ Number of experiment } & $\mathbf{1}$ & $\mathbf{2}$ & $\mathbf{3}$ & $\mathbf{4}$ & $\mathbf{5}$ \\
\cline { 2 - 6 } & $\mathbf{H I} / \mathbf{d l}$ & $\mathbf{H I} / \mathbf{d} 2$ & $\mathbf{H I} / \mathbf{d} 3$ & $\mathbf{H I} / \mathbf{d} 4$ & $\mathbf{H I} / \mathbf{d 5}$ \\
\hline $\mathrm{H} / \mathrm{d}$ & 2.5 & 1.9 & 1.5 & 1.3 & 1.1 \\
\hline E. $\%$ & 42 & 38 & 35 & 45 & 40 \\
\hline & $\mathrm{H} 2 / \mathrm{d} \mathbf{l}$ & $\mathrm{H} 2 / \mathrm{d} 2$ & $\mathrm{H} 2 / \mathrm{d} 3$ & $\mathrm{H} 2 / \mathrm{d} 4$ & $\mathrm{H} 2 / \mathrm{d} 5$ \\
\hline H/d & 3.3 & 2.5 & 2.0 & 1.7 & 1.4 \\
\hline E. $\%$ & 82 & 55 & 37 & 32 & 30 \\
\hline & $\mathrm{H} 3 / \mathrm{dl}$ & $\mathrm{H} 3 / \mathrm{d} 2$ & $\mathrm{H} 3 / \mathrm{d} 3$ & $\mathrm{H} 3 / \mathrm{d} 4$ & $\mathrm{H} 3 / \mathrm{d} 5$ \\
\hline H/d & 5.0 & 3.8 & 3.0 & 2.5 & 2.1 \\
\hline E. $\%$ & 32 & 82 & 85 & 76 & 66 \\
\hline H/d & $\mathrm{H} 4 / \mathrm{dl}$ & $\mathrm{H} 4 / \mathrm{d} 2$ & $\mathrm{H} 4 / \mathrm{d} 3$ & $\mathrm{H} 4 / \mathrm{d} 4$ & $\mathrm{H} 4 / \mathrm{d} 5$ \\
\hline E. $\%$ & 6.7 & 5.0 & 4.0 & 3.3 & 2.9 \\
\hline & 50 & 56 & 90 & 92 & 88 \\
\hline H/d & $\mathrm{H} 5 / \mathrm{d} 1$ & $\mathrm{H} 5 / \mathrm{d} 2$ & $\mathrm{H} 5 / \mathrm{d} 3$ & $\mathrm{H} 5 / \mathrm{d} 4$ & $\mathrm{H} 5 / \mathrm{d} 5$ \\
\hline E. $\%$ & 8.3 & 6.3 & 5.0 & 4.2 & 3.6 \\
\hline & 50 & 53 & 60 & 78 & 86 \\
\hline
\end{tabular}

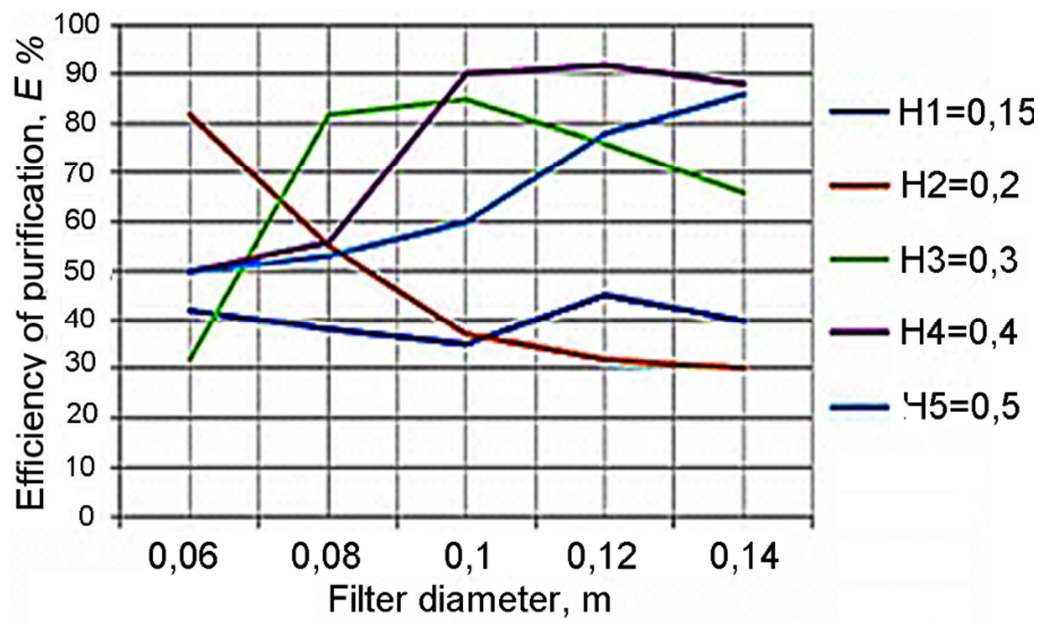

Fig. 6. The dependence of the biogas purification efficiency on the $\mathrm{H} / \mathrm{d}$ filter ratio.

The experimental studies have shown that the maximum efficiency of the biogas purification is obtained with the ratio of the height and diameter of the filter housing $\mathrm{H} / \mathrm{d}=$ 3.0: 4.2 .

For theoretical research, the second-order planning is used, which allows to obtain a response surface. To implement the experiment, a non-composite second-order plan for three factors is used. After calculating the regression coefficients, the equation has been obtained:

$$
\begin{gathered}
\mathrm{Y}=14,1635+18,9471 * \mathrm{x}+0,1051 * \mathrm{y}-2,3606 * \mathrm{x}^{2}-0,0035 * \mathrm{x} * \mathrm{y} \\
-5,5077 \mathrm{E}-5 * \mathrm{y}^{2}
\end{gathered}
$$

The assessment of the adequacy of theoretical and experimental studies was carried out according to the Fisher criterion, where Fcalc $=0.25 \mathrm{Ftabl}=3.22$ with $95 \%$ validity. Therefore, the hypothesis of the adequacy of equation (2) can be considered true. The standard error did not exceed 3.5\%. 
The canonical analysis of the mathematical model (2) made it possible to obtain a visual representation of the geometric image of the studied response function. After considering the influence of factors $x 1$ and $x 2$ on the efficiency indicator of the biogas purification with stabilization of $\mathrm{x} 3$ at zero level and differentiation with respect to $\mathrm{x} 1$ and $\mathrm{x} 2$ the equation (2) in canonical form has:

$$
\begin{gathered}
\mathrm{Y}=14,1635+0,1051 * \mathrm{x}+18,9471 * \mathrm{y}-5,5077 \mathrm{E}-5 * \mathrm{x}^{2}-0,0035 * \mathrm{x} * \mathrm{y} \\
-2,3606 * \mathrm{y}^{2}
\end{gathered}
$$

The canonical equation (3) in geometric form was represented as an elliptical paraboloid, the surface having an extremum. Moreover, the coefficients of the equation have the same signs, and the center of the figure is near the center of the experiment (Figure 7).

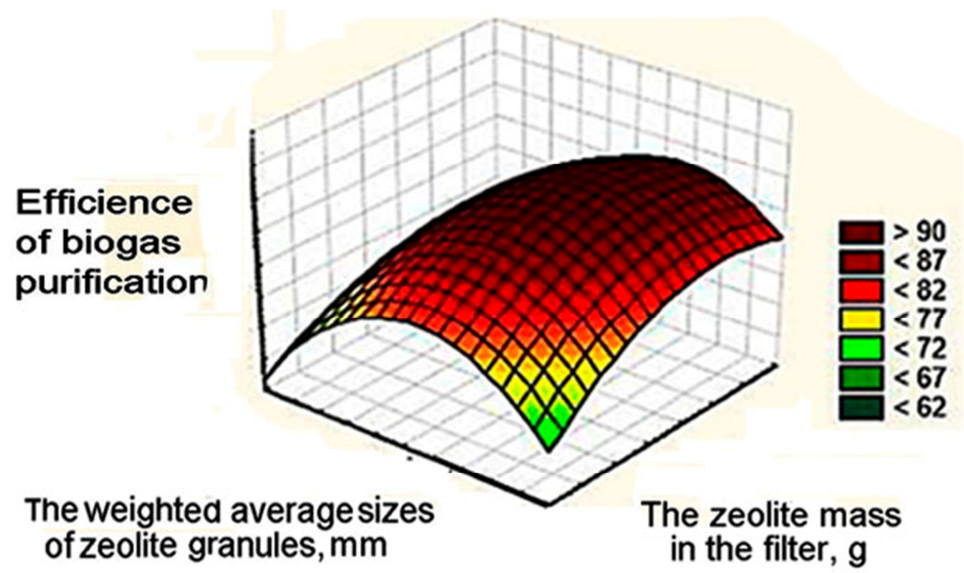

Fig. 7. The response surface characterizing the biogas $(Y)$ purification efficiency depending on the weighted average sizes of zeolite granules (X1) and the zeolite mass in the filter (X2) at (X3) at zero level.

Having considered the influence of factors $x 1$ and $x 3$ during stabilization of $\mathrm{x} 2$, after mathematical transformations, the canonical equation is obtained:

$$
\begin{gathered}
\mathrm{Y}=55,6139+14,9792 * \mathrm{x}+3,4889 * \mathrm{y}-2,3281 * \mathrm{x}^{2}+0,3333 * \mathrm{x} * \mathrm{y} \\
-0,5778 * \mathrm{y}^{2}
\end{gathered}
$$

By analogy, equation (4) in a geometric image is an elliptical paraboloid whose surface has an extremum, and the coefficients of the equation have the same signs. The center of the figure is near the center of the experiment (Figure 8). 




Fig. 8. The response surface characterizing the efficiency of the biogas purification (Y) depending on the weighted average sizes of the zeolite granules (X1) and the ratio of filter height to diameter (X3) at (X2) at zero level.

When considering the influence of factors $x 2$ and $x 3$ during stabilization of $x 1$, the equation (4) after the transformations is in canonical form:

$$
\begin{gathered}
\mathrm{Y}=92,9264+0,0693 * \mathrm{x}-25,8444 * \mathrm{y}-2,9 \mathrm{E}-5 * \mathrm{x}^{2}-0,0053 * \mathrm{x} * \mathrm{y} \\
+4,7556 * \mathrm{y}^{2}
\end{gathered}
$$

The equation (5) in geometric image is elliptical paraboloid with the surface having extremum, the equation coefficients have the same signs, and the center of the figure is near the center of the experiment (Figure 9) [13].

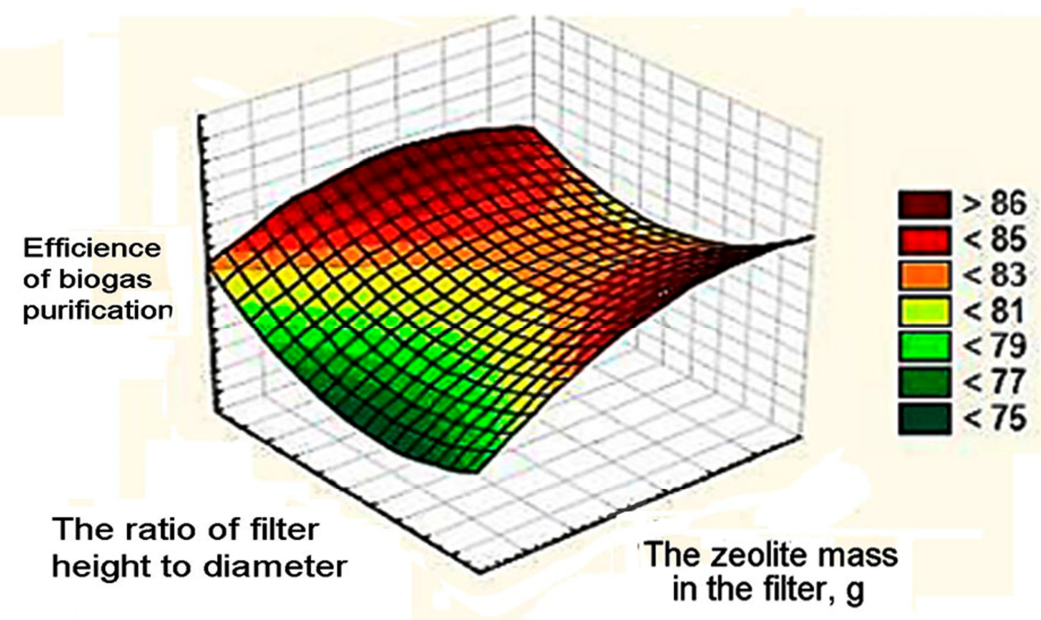

Fig. 9. The response surface characterizing the efficiency of the biogas purification $(\mathrm{Y})$ depending on the zeolite mass (X2) and the ratio of filter height to diameter (X3) at (X1) at zero level.

\section{Discussion}

Biogas is a high-quality alternative fuel. Since biogas consists mainly of methane, it is easy to adapt it to all processes where natural gas is used. The biogas is one of the most 
environmentally friendly types of motor fuel. Compared to other types of petroleum fuels, during engine operation the biogas produces the smallest amount of carbon dioxide and particulate matter. A gas-fueled engine is known to run quieter and it vibrates less than an oil engine, which improves the working conditions of machine operators and provides environmental safety, reduces the risk of fires and explosiveness [16-21].

The leader in the use of biogas is China, which in the 70s of the 20th century made a "big biogas jump", as a result of which more than $60 \%$ of the country's total number of automobiles including in rural areas, works on biogas. The production of biogas engines in China by the end of the 80 s of the 20 th century was classified. China currently exports them to more than 20 countries.

In remote rural areas, it is possible to use biogas as an alternative fuel for refueling tractor equipment, for combustion in heating boilers, in gas heating rings for heating water.

The conducted studies have shown that the biogas obtained from manure processing can be used as an alternative gas fuel for internal combustion engines. At the same time, the quality of biogas can be improved using the filtration method. The natural zeolite of the "Khongurite" brand may be used as filtering material. In the conducted studies a good filtering ability of this material for the biogas purification from unnecessary impurities has been proved. As well as increasing the concentration of the useful component - methane. The experimental studies have shown that the maximum efficiency of biogas purification is obtained with the ratio between the height and diameter of the filter $\mathbf{H} / \mathbf{d}=\mathbf{3 . 0}: 4.2$. The optimum weighted average diameter of the granules of the bulk filter material (zeolite) is $0.004 \mathrm{~m}$. The optimum mass of the filter material is $0.75-0.8 \mathrm{~kg}$. Moreover, the degree of the biogas purification is maximum.

\section{References}

1. E.V. Karatayeva, V.V. Anshakova, Science and education 2, 65 (2013)

2. O.W. Awe, Y. Zhao, A. Nzihou, et al., Waste Biomass Valor 8, 267-283 (2017) https://doi.org/10.1007/s12649-016-9826-44

3. I.V. Bardamova, The 19th International Symposium Ecology \& Safety, Journal of International Scientific Publications Ecology \& Safety 4(3), 445-451 (2019) ISSN: 1313-2563, http://www.science-journals.eu/ecology/index.html

4. A. Kabata-Pendias, Trace Elements in soils and plants. Boca Raton (CRC Press, Taylor and Francis Group, London, N.Y., 2011)

5. M.E. Afilal, O. Elasri, Z. Merzak, J. Mater. Environ. Sci. 5, 1160-1169 (2014)

6. O. El Asri, I. Hafidi, M. Afilal, Waste Biomass Valor 6, 459-464 (2015) https://doi.org/10.1007/s12649-015-9378-z

7. H. Herrmann, H. Bucksch, Dictionary Geotechnical Engineer, Wörtebuch GeoTechnik (Hardcover, 2014) ISBN: 978-3-642-41713-9

8. V.I. Zemskov, G.M. Kharchenko, Bulletin of the Altai State Agrarian University 4, 148 (2014)

9. X. Zou, G. Zhu, Microporous Materials for Separation Membranes First (2019) DOI:10.1002/9783527343997

10. V.P. Druzyanova, S.A. Petrova, M.K. Okhlopkova, Scientific Review (Moscow, 2014)

11. O.P. Semenova, V.P. Druzhyanova, E.N. Kobyakova, Scientific problems of transport in Siberia and the Far East. (Novosibirsk, 2015)

12. N. Draper, H. Smith, Applied regression analysis (Translated edition) (Dialectics, 2017) 
13. Russian Federation Standard GOST 5542-2014 (Standartinform, Moscow, 2015)

14. O.P. Semenova, D.N. Radnaev, Bulletin of the Buryat State Agricultural Academy named after V.R. Filippov 3(44), 88-91 (2016)

15. O.P. Semenova, Aeconomics: Economics and Agriculture 4(12), 13 (2016) http://aeconomy.ru

16. Viking Strategies. Farm to fuel. Developers' guide to bio-methane as a vehicle fuel. Biogas Assoc (2013) http://vikingstrategies.ca/documents/DeveloperGuide-BiomethaneVehicleFuel.pdf.

17. A. Pantaleo, B. De Gennaro, N. Shah, Renew. Sustain. Energy Rev. 20, 57-70 (2013)

18. O.W. Awe, Y. Zhao, A. Nzihou et al., Waste Biomass Valor 8, 267-283 (2017) https://doi.org/10.1007/s12649-016-9826-4

19. Energoklastr (2015) from http://www.cleargas.cz/en.pdf

20. L. Yang, X. Ge, C. Wan, F. Yu, Y. Li, Renew Sustain Energy Rev. 40, $1133-$ 1152 (2014) https://doi.org/10.1016/j.rser.2014.08.008

21. D. Balussou, T. Heffels, R. McKenna et al., Waste Biomass Valor 5, 743-758 (2014) 